\title{
Cognitive, Behavioral, and Neural Consequences of Sex Chromosome Aneuploidy
}

\author{
Frida Printzlau, Jeanne Wolstencroft, and David H. Skuse* \\ Great Ormond Street Hospital Institute of Child Health, University College London, United Kingdom
}

The $\mathrm{X}$ chromosome has played a critical role in the development of sexually selected characteristics for over 300 million years, and during that time it has accumulated a disproportionate number of genes concerned with mental functions. There are relatively specific effects of $\mathrm{X}$-linked genes on social cognition, language, emotional regulation, visuospatial, and numerical skills. Many human X-linked genes outside the $\mathrm{X}-\mathrm{Y}$ pairing pseudoautosomal regions escape $\mathrm{X}$-inactivation. Dosage differences in the expression of such genes (which constitute at least $15 \%$ of the total) are likely to play an important role in male- female neural differentiation, and in cognitive deficits and behavioral characteristics, particularly in the realm of social communication, that are associated with sex chromosome aneuploidies. VC 2016 Wiley Periodicals, Inc.

Key words: X chromosome; Y chromosome; autism; ADHD; language

\section{Role of the $\mathrm{X}$ chromosome in brain development}

The autosomes and the sex chromosomes differ in their evolutionary origins, and that fact may have implications for the distinct contribution made by the X chromosome to mental functioning (Skuse, 2005). There are estimated to be 824 coding genes on the X chromosome (Ensembl release 84, March 2016, http://www.ensembl. org), just over $4 \%$ of all genes. In 2016, Online Mendelian Inheritance in Man recorded 2,241 entries for mental retardation. Of these, 502 (22.3\%) are described as being X-linked (Wu et al., 2014), suggesting that genes on the $\mathrm{X}$ chromosome could play a disproportionate role in the development of human intelligence (Johnson et al., 2009). Why should there be such a concentration on this particular chromosome? The Y chromosome has just 72 coding genes (Ensembl release 84, March 2016), and no mutations are associated directly with a mental retardation syndrome, although, as we will discuss, there is good evidence that the $\mathrm{Y}$ chromosome does play a role in brain development and that $\mathrm{X}-\mathrm{Y}$ pairs of genes are critically important in gene regulation elsewhere in the genome.

The mechanism of sexual differentiation of the brain depends not just on the action of gonadal hormones; there is increasing evidence that genes encoded by the sex chromosomes also play an important role. Lin et al. (2015) pointed out that neuroimaging analysis of humans with sex chromosome aneuploidies has shown that the $\mathrm{X}$ and $\mathrm{Y}$ chromosomes may have opposing effects on cortical development and cortical thickness asymmetry. Several Y chromosome encoded genes (especially PCDH11Y and NLGN4Y) may play a critical role; these genes have been linked to the risk of psychiatric disorders for many years (Kopsida et al., 2009; Crow, 2013). Recent research has found that their X and Y homologues are expressed in different glial and neuronal cell populations in the central nervous system during human male embryonic

\section{SIGNIFICANCE}

Sex differences in a range of skills that constitute our intellectual strengths and weaknesses, as well as social behavior and language, are influenced by genes that lie on the $\mathrm{X}$ and $\mathrm{Y}$ chromosomes. The possession of just one $\mathrm{X}$ chromosome greatly increases the risk of social communication problems. This genetic condition is typical of XY males, and also of XO females with Turner syndrome. The greatest impact of an anomalous number of sex chromosomes is on intellectual abilities, presumably because of dosage imbalance in key X- or Y-linked genes, but most of those genes have yet to be identified.

Support/grant information: Intellectual Disability and Mental Health: Assessing Genomic Impact on Neurodevelopment (IMAGINE): grant ref: MR/N022572/1. Funder: Medical Research Council (UK), Medical Research Foundation (UK).

*Correspondence to: Professor David H. Skuse, Behavioural and Brain Sciences Unit, Institute of Child Health, 30 Guilford Street, London WC1N 1EH, United Kingdom. E-mail: d.skuse@ucl.ac.uk Received 14 June 2016; Revised 25 August 2016; Accepted 6 September 2016.

Published online 7 November 2016 in Wiley Online Library. (wileyonlinelibrary.com). DOI: 10.1002/jnr.23951

[Type here] 
development (Berletch et al., 2015; Johansson et al., 2016).

The theory that the $\mathrm{X}$ chromosome might harbor genes that played an important role in the development of intelligence was first proposed by Lehrke (1972). It is well recognized that certain cognitive skills are more variable in males than in females (Hedges and Nowell, 1995), and this variability has been ascribed to the influence of genes on the X chromosome (Johnson et al., 2009). Many studies have found that quantitative skills and visuospatial abilities are particularly variable in typical males compared with typical females, and (as will be discussed here in further detail) evidence from sex chromosome aneuploidies points to dosage-sensitive genetic influences on both nonverbal skills and verbal skills. Epidemiological data also appear to show that there is greater variability in general intelligence among males at both ends of the IQ spectrum (Johnson et al., 2009). Although there is no doubt that X-linked mental retardation is more common among males because of the undue impact of X-linked genetic mutations on their X-monosomic status, there is less good evidence that X-linked gene variants contribute to the small excess of males at the upper end of the general IQ distribution as well (Giummo and Johnson, 2012).

Although the evidence is overwhelming that there is an accumulation of genes on the $\mathrm{X}$ chromosome that are important for "normal" brain development, there are mixed opinions about the hypothesis that multiple rare mutations could explain the observed excess of high-IQ males at the upper end of the IQ distribution (Craig et al., 2009). Nevertheless, it is plausible that multiple alleles act additively to increase or reduce intelligence, and theoretically could contribute to a relatively bimodal distribution of intelligence in males, compared with the unimodal distribution typical of females. A single explanation for the excess of males at the upper and lower ends of the IQ distribution is not likely, as different alleles would have to be involved (one enhancing, one reducing IQ, or IQ-related traits). There is also a potential role for the impact of random X-inactivation. Daughter cells of the active X chromosome carry the same pattern of inactivation as the cell from which they were derived. This can lead to tissue-specific skewing because a particular pattern of selection could favor tissues that require the "best-functioning" copy of an X-linked allele, thereby increasing allelic homozygosity in those tissues. The extent to which female human brains are mosaic, in the sense that different brain regions are developed from cells in which one or the other parental X chromosome is selected to remain active (Migeon, 2014), is not known, although there is evidence that mouse brains do have regional sex-specific parentof-origin allelic expression (Gregg et al., 2010; Wu et al., 2014).

Eutherians (placental mammals) have very small regions of identical $\mathrm{X}-\mathrm{Y}$ homology, situated at the tips of the $\mathrm{X}$ and $\mathrm{Y}$ chromosomes that remain capable of meiotic recombination. These are known as the pseudoautosomal regions or PAR1 (on the Y chromosome short arm) and PAR2 (on the long arm) (Disteche, 2012). Both X and Y copies are expressed in normal males and females, and in the PAR there is gene dosage equivalence (Johnston et al., 2008). Most genes elsewhere on the randomly inactivated $\mathrm{X}$ chromosome in females are silenced, although some have paralogs elsewhere on the Y chromosome. Overall, about 15\% escape X-inactivation in humans. There are no significant differences in overall expression levels of escape genes compared with inactivated genes in males, who have only the one $\mathrm{X}$ chromosome and so might be thought to be at risk of haploinsufficiency. This implies that genes outside the PAR are upregulated on the male's X where necessary for normal function (Disteche, 2012). It is possible that the Y paralog of the equivalent $\mathrm{X}$-linked gene is not performing an identical function, but that it has become important for male differentiation, a question that has not been answered yet.

Proportionately, the largest number of such "escapee" genes lie on the short arm (Xp) (Deng et al., 2014), which evolved relatively recently, the most distal region 30 to 50 million years ago, whereas eutheria diverged from metatheria (marsupials) 130 million years ago. Noninactivated genes on the $\mathrm{X}$ chromosome that lack a $\mathrm{Y}$ homologue are potential candidates for sexual dimorphism. It should be possible to learn more about their functions in humans by studying females who have but a single X chromosome (Turner syndrome) and who would, therefore, be haploinsufficient for their products. Genes that escape X-inactivation are good candidates for the dosage-mediated phenotypic disruptions that are associated with sex chromosome aneuploidies (Zhang et al, 2013). As discussed, such genes could play a critical role in the development of the brain and of consequent mental abilities. Y-linked genes also escape Xinactivation and, when involved in aneuploidies, could suffer dosage imbalance that contributes to anomalous brain 
TABLE I. IQ Score Mean Values, Across Studies, by Sex Chromosome Aneuploidy

\begin{tabular}{|c|c|c|c|}
\hline & $\begin{array}{c}\text { Full-scale IQ: } \\
\text { general intelligence }\end{array}$ & $\begin{array}{l}\text { Verbal IQ: } \\
\text { verbal skills }\end{array}$ & $\begin{array}{c}\text { Performance IQ: } \\
\text { nonverbal skills }\end{array}$ \\
\hline \multirow[t]{3}{*}{$\mathrm{XO}$} & 90-94 & 93-99 & 88-91 \\
\hline & (Hong et al., 2011; & (Hong et al., 2011; & (Rovet, 1993; \\
\hline & Rovet, 1990, 1993) & Rovet, 1993) & Hong et al., 2011) \\
\hline \multirow[t]{3}{*}{ XYY } & $91-97$ & $88-92$ & 95-102 \\
\hline & (Bardsley et al., 2013; & (Bardsley et al., 2013; & (Bardsley et al., 2013; \\
\hline & Tartaglia et al., 2012) & Tartaglia et al., 2012) & Tartaglia et al., 2012) \\
\hline \multirow[t]{3}{*}{$\mathrm{XXY}$} & $92-98$ & $84-93$ & 98-99 \\
\hline & (Rovet et al., 1995; & (Rovet et al., 1995; & (Rovet et al., 1995; \\
\hline & Tartaglia et al., 2012) & Tartaglia et al., 2012) & Tartaglia et al., 2012) \\
\hline \multirow[t]{3}{*}{$\mathrm{XXX}$} & $83-93$ & $82-87$ & $87-100$ \\
\hline & (Tartaglia et al., 2012; & (Tartaglia et al., 2012; & (Tartaglia et al., 2012; \\
\hline & Tartaglia et al., 2010b) & Rovet et al., 1995) & Rovet et al., 1995) \\
\hline \multirow[t]{3}{*}{ XXYY } & $78-79$ & $74-77$ & $84-87$ \\
\hline & (Tartaglia et al., 2008b; & (Tartaglia et al., 2008b; & (Tartaglia et al., 2008b; \\
\hline & Tartaglia et al., 2012) & Tartaglia et al., 2012) & Tartaglia et al., 2012) \\
\hline
\end{tabular}

development (Raznahan et al., 2016), although the specific role of Y-linked genes in human brain is not well understood. Zhang et al. (2013) identified 22 genes that normally escape X-inactivation in females and are involved in brain development. They may be dosage sensitive; if mutated, the resulting condition is one of intellectual disability. However, the cognitive and behavioral consequences of sex chromosome anomalies such as XYY and XXYY syndromes are presumably due to equivalent disrupted processes that involve the Y chromosome as well.

It is important to note that even within populations of similar recent evolutionary origin (e.g., Europeans), there are significant differences between females in some proportion of $\mathrm{X}$-linked genes that escape inactivation; these may differ between tissues and even over the life span (Berletch et al., 2015). Y-linked homologues are considerably more common for genes that always escape X-inactivation, but within the female population it appears some are "hyperescapees" and some are "hypo-escapees" (Zhang et al, 2013). Clearly, this fact has implications for the variation in degree of phenotypic abnormality observed between individuals with syndromes of poly-X aneuploidy.

\section{Cognition and behaviour in sex chromosome aneuploidie}

Cognitive abilities among individuals with sex chromosome aneuploidies are highly variable. For instance, full scale IQ is within the average range in some conditions (e.g., Turner syndrome, XYY), but it is significantly impaired in others (e.g., XXYY syndrome). Depending on the configuration of aneuploidy involvement of X and/or Y chromosomes, the syndrome manifests in differential effects on verbal and nonverbal skills. The fact that, in behavioral and cognitive terms, there are specific deficits associated with each condition might provide clues to the role of X- (and Y-) linked genes in different aspects of intellectual development (see Table I).

It has often been assumed that every supernumerary $\mathrm{X}$ chromosome increases the severity of the cognitive phenotype (Linden et al., 1995), with a one-standard deviation reduction in full-scale IQ scores per additional X, when the affected individual is compared with his or her siblings (Polani, 1977; Bender et al., 1993). However, this finding must be interpreted carefully in light of ascertainment biases. Most aneuploidies go clinically unnoticed (Ratcliffe, 1999); birth cohorts studies have shown that XXX and XYY have incidence rates of 1 in 1,000 female and male live births, respectively, yet only 10\% of cases are clinically ascertained (Nielsen and Wohlert, 1991; Abramsky and Chapple, 1997).

XXYY males tend to have lower-than-expected IQ scores compared with XXX females, suggesting that the severity of their phenotype cannot be fully attributed to the number of supernumerary X chromosomes. As mentioned, the observation is consistent with recent evidence that genes on the Y chromosome play an important and potentially 
independent role (from the $\mathrm{X}$ chromosome) in brain development (Berletch et al., 2015). The gene content of the $\mathrm{Y}$ chromosome has evolved to maintain the ancestral dosage of homologous $\mathrm{X}-\mathrm{Y}$ gene pairs, and those pairs are broadly expressed regulators of gene function; they can govern expression of targets throughout the genome (Bellott et al., 2014).

Other factors influencing IQ scores among individuals with sex chromosome aneuploidies should not be overlooked. These include genetic background, socioeconomic status (SES), and age at which the diagnosis was made. IQ is highly heritable, and in some autosomal genetic conditions where the cognitive phenotype is very variable, biparental IQ has been shown to correlate with the child's IQ (Moreno-De-Luca et al., 2015). It is likely that this is also true in sex chromosome aneuploidies and contributes to the cognitive heterogeneity observed within each disorder.

In certain genetic disorders, the age of diagnosis may also have an impact on IQ. In XYY the average IQ score of children diagnosed prenatally is higher (by up to 17 points) than in children diagnosed in childhood (Bardsley et al., 2013). The causes for this difference are likely to be multiple and are likely to be influenced by SES, parental genetic background, and ascertainment bias, but few aneuploidy studies have systematically compared IQ scores and their relationship to age of diagnosis. Cases of XYY syndrome diagnosed prenatally are mostly found by chance, whereas those who are diagnosed in later childhood come to attention because of cognitive and behavioral problems (Tokita and Sybert, 2016).

The relative impact of sex chromosome aneuploidies on broad classes of intellectual ability is well recognized, but little understood. In the male aneuploidies (XXY, XYY, and XXYY), there is a relative deficit in verbal compared with visuospatial ability (see Table I). In contrast, the condition of X monosomy is associated with better verbal than visuospatial skills. Females with XXX syndrome are impaired in both verbal and visuospatial domains, with a relative

TABLE II. Percent Reported to Have Diagnosis or Meet Diagnostic Criteria for Autism Spectrum Disorder (ASD) and Attention-Deficit/Hyperactivity Disorder (ADHD)

\begin{tabular}{cccccc}
\hline & XO & XXY & XYY & XXX & XXYY \\
\hline ASD & $3 \%-4 \%$ & $11 \%-27 \%$ & $19 \%-36 \%$ & No increased risk & $28 \%-34 \%$ \\
& (Creswell and Skuse, 1999; & (Bruining et al., 2009; & (Bishop et al., 2011; & (Bishop et al., 2011) & (Tartaglia et al., 2008a; \\
& Saad et al., 2013) & Bishop et al., 2011) & Tartaglia et al., 2012) & Tartaglia et al., 2012) \\
ADHD & $20 \%-50 \%$ & $36 \%-63 \%$ & $46 \%-76 \%$ & $25 \%-52 \%$ & $72.2 \%$ \\
& (Green et al., 2015; & (Bruining et al., 2009; & (Ross et al., 2012; & (Bender et al., 1993; $\quad$ (Tartaglia et al., 2012) \\
& Saad et al., 2013) & Tartaglia et al., 2010a) & Tartaglia et al., 2012) & Tartaglia et al., 2012) \\
\hline
\end{tabular}

deficit in their verbal abilities, like their male counterparts with sex chromosome aneuploidies (see Table I). Intriguingly, the visuospatial and verbal components of IQ may not remain stable over time. In XXYY, verbal IQ appears to decrease with age whilst visuospatial IQ remains relatively stable over time (6 to 201 age range [Tartaglia et al., 2008b]). More research is needed to establish the development of sex chromosome aneuploidy IQ profiles throughout the life span.

This pattern of imbalance between visuospatial and verbal skill IQ scores in different sex chromosome aneuploidies is reflected in terms of language abilities. With the exception of X monosomy, all the aneuploidies are associated with language delay in childhood (Bender et al., 1983; Geerts et al., 2003; Tartaglia et al., 2008b; Bishop and Scerif, 2011; Bishop et al., 2011) and a trend towards a more severe deficit in expressive than receptive language skills. Both XXY and XXX syndromes have been associated with auditory processing disorders (Bender et al., 1983; Graham et al., 1988). The difficulties seen in XXY syndrome are similar to the deficits seen in typically developing children who have specific language impairments (Bishop and Scerif, 2011). More research needs to be conducted to pinpoint the specific genetic influences on these language-processing difficulties.

Interestingly, Turner syndrome appears to confer specific advantages in the development of language; in childhood, affected girls can perform better than typically developing girls in terms of receptive and expressive language tasks, phonological tasks, and lexico-semantic language tasks. On the other hand, they perform worse on 
some executive function tasks such as speeded number naming (Temple and Shephard, 2012). The lexicosemantic advantage is preserved in early adulthood, but specific difficulties with executive tasks become more apparent as they grow older (Temple and Shephard, 2012). This suggests that X-linked gene haploinsufficiency may confer an early advantage for receptive and expressive language skills, phonological skills, and lexicosemantic processing. However, there are also hormonal consequences of X monosomy, because it leads to atretic ovaries, so sex hormone abnormalities could be a contributory factor to the unusual pattern of cognitive skills and weaknesses.

The role played in X monosomy-associated cognitive strengths and weaknesses by specific X-linked genes that are haploinsufficient is not clear; potentially, haploinsufficiency could be caused by genes that are normally expressed on both $\mathrm{X}$ chromosomes in females and that escape $\mathrm{X}$-inactivation. If any of those genes were important for neurodevelopment and were dosage sensitive, that could potentially explain the expressive and receptive language deficits observed in XXX syndrome. From a comparison of strengths and weaknesses shown in Table I, the implication is that their downregulation is not possible but that upregulation is possible.

\section{Behavior: autism spectrum disorder and attention-deficit/ hyperactivity disorder}

Males and females show different susceptibilities to mental health issues, and in neurodevelopmental disorders such as autism spectrum disorder (ASD) and attention-deficit/ hyperactivity disorder (ADHD), these sex differences are particularly noticeable.

In a 2009 review of the epidemiology of ASD, the male: female ratio was reported to be 4:1 (Fombonne, 2009). In April 2016, the US Centers for Disease Control and Prevention reported that ASD is still found to be about 4.5 times more common in boys than in girls in clinically identified samples (Christensen et al., 2016). ADHD is equally male biased in clinical populations; there are approximately five times as many ADHD diagnoses in boys than girls in Europe (Nøvik et al., 2006). These sex differences suggest that X-linked genes may play a role in the predisposition to mental disorders in general and in male susceptibility to neurodevelopmental disorders in particular.

Table II shows the prevalence of ASD and ADHD in individuals with sex chromosome aneuploidies. With the exception of XXX syndrome, sex chromosome aneuploidies are consistently associated with increased risk of ADHD and ASD. Girls with Turner syndrome may have a 200-fold increased risk of ASD relative to the general female population (Creswell and Skuse, 1999). For males with sex chromosome aneuploidies, the estimated increased risk for ASD ranges from a 10-fold increase for XXY males to a 20- to 30-fold increase for XYY males (Bishop et al., 2011)

TABLE III. Total Brain Volume and White and Gray Matter Characteristics of Individuals with Sex Chromosome Aneuploidies

\begin{tabular}{|c|c|c|c|}
\hline & Total brain volume & White matter & Gray matter \\
\hline $\mathrm{XO}$ & $\begin{array}{l}\text { No difference } \\
\text { (Marzelli et al., 2011) }\end{array}$ & $\begin{array}{l}\text { Reduced in parietal and occipital } \\
\text { regions } \\
\text { (Cutter et al., 2006; Lepage et al., } \\
2013 \text { ) } \\
\text { Increased in temporal and } \\
\text { orbitofrontal lobes } \\
\text { (Cutter et al., 2006) }\end{array}$ & $\begin{array}{l}\text { Reduced in parietal and occipital } \\
\text { regions } \\
\text { (Cutter et al., 2006; Lepage et al., } \\
\text { 2013) } \\
\text { Increased in cerebellar hemispheres } \\
\text { (Brown et al., 2002; Cutter et al., } \\
\text { 2006) }\end{array}$ \\
\hline XYY & $\begin{array}{l}\text { No difference } \\
\text { (Warwick et al., 1999) to increased } \\
\text { (Bryant et al., 2012) }\end{array}$ & $\begin{array}{l}\text { Increased } \\
\text { (Bryant et al., 2012) }\end{array}$ & $\begin{array}{l}\text { Increased } \\
\text { (Bryant et al., 2012) }\end{array}$ \\
\hline XXY & $\begin{array}{l}\text { Reduced } \\
\text { (Warwick et al., 1999; DeLisi et al., } \\
\text { 2005; Giedd et al., 2007) }\end{array}$ & $\begin{array}{l}\text { Reduced } \\
\text { (Warwick et al., 1999) }\end{array}$ & $\begin{array}{l}\text { Reduced } \\
\text { (Patwardhan et al., 2000) }\end{array}$ \\
\hline $\mathrm{XXX}$ & $\begin{array}{l}\text { Reduced } \\
\text { (Warwick et al., 1999; Patwardhan } \\
\text { et al., 2002; Lenroot et al., 2014) }\end{array}$ & $\begin{array}{l}\text { Reduced } \\
\text { (Lenroot et al., 2014) }\end{array}$ & $\begin{array}{l}\text { Reduced in all areas except parietal } \\
\text { lobe } \\
\text { (Lenroot et al., 2014) }\end{array}$ \\
\hline XXYY & $\begin{array}{l}\text { Reduced } \\
\text { (Hanley et al., 2015) }\end{array}$ & $\begin{array}{l}\text { WM hyperintensities } \\
\text { (Tartaglia et al., 2008b) } \\
\text { Reduced in temporal and frontal } \\
\text { lobes, increased in parietal lobe } \\
\text { (Hanley et al., 2015) }\end{array}$ & $\begin{array}{l}\text { Reduced in temporal and frontal } \\
\text { lobes, increased in parietal lobe } \\
\text { (Hanley et al., 2015) }\end{array}$ \\
\hline
\end{tabular}


and XXYY males (Tartaglia et al., 2008b,). The literature on the behavioral phenotype for XXX syndrome is limited (Otter et al., 2010), but existing evidence does not seem to link XXX with an increased risk of ASD (Bishop et al., 2011).

There is also evidence to suggest that girls with Turner syndrome and males with sex chromosome aneuploidies show autistic traits and subtle social communication deficits even when the diagnostic criteria for ASD are not met. Studies of males with sex chromosome aneuploidies have revealed high rates of subclinical social communication difficulties (Bishop et al., 2011; Cordeiro et al., 2012; Ross et al., 2012). Girls with Turner syndrome show impaired "theory of mind" skills, meaning that they tend to lack the ability to understand other people's mental experiences (Lawrence et al., 2003). They also have social and emotional difficulties (Skuse, 2009; Burnett et al., 2010) as well as problems forming and maintaining relationships with peers (Hong et al., 2011). However, there are occasional contrary findings; for instance, Lepage and colleagues (2014) did not find any difference between girls with Turner syndrome and healthy controls in terms of autistic or empathic traits.

Several authors have suggested that genes expressed from the Y chromosomes contribute directly or indirectly to the elevated risk of ASD/ADHD in males (Cordeiro et al., 2012; Margari et al., 2014). Their hypothesis would, if true, go some way to explaining why there are relatively more commonly problems with ASD identified in males with XYY compared with males with Klinefelter syndrome (XXY) (Ross et al, 2015). An alternative hypothesis is that the presence of a second $X$ chromosome serves a protective function for neurodevelopmental disorders (Skuse, 2005). This would also explain why girls with X monosomy, but not those with XXX syndrome, show an increased risk of ASD. Several X-linked genes have been linked to the risk of ASD including NLGN3 on Xq13 and NLGN4 on Xq22.39 (Talebizadeh et al., 2006). Neuroligins have homologues on the Y chromosome, and Bishop and colleagues (2011) have suggested that both X-linked and Y-linked neuroligins play important roles in the aetiology of ASD and other communication disorders.

Epigenetic effects on the $\mathrm{X}$ chromosome, such as imprinting, have also been proposed to play a role in the development of individual differences in social cognition (Skuse, 2005). Imprinting refers to the silencing of either maternally or paternally inherited alleles. In males, the X chromosome is necessarily inherited from the mother and the $\mathrm{Y}$ chromosome from the father. In females, one $\mathrm{X}$ is from the mother and the other $\mathrm{X}$ is from the father. In typical females, gene expression from the $\mathrm{X}$ chromosome is equally likely by chance to be from the paternally or the maternally derived allele. In contrast, in Xmonosomic Turner syndrome, the single X chromosome is inherited either from the father or the mother. Skuse and colleagues (1997) found that girls with Turner syndrome with a maternally inherited X chromosome showed greater impairment of social cognition compared with girls with Turner syndrome who had a paternally inherited X, suggesting that imprinting effects relating to silencing of certain genes may be a contributing factor to sex differences in ASD prevalence.

\section{Brain structure}

The largest sex difference in brain structure between males and females is in overall brain size (Giedd et al., 1997). A recent meta-analysis reported that intracranial volume is about $12 \%$ larger for males than females and that total brain volume (TBV) is about $10 \%$ larger for males than for females (Ruigrok et al., 2014). X-linked genes, hormonal factors, and environmental factors are all likely contributors to the difference in brain size between males and females.

Individuals with sex chromosome aneuploidies tend to show differences in brain structure relative to healthy controls (see Table III). Individuals with XXY, XXX, and XXYY all show reduced TBV (Warwick et al., 1999; Hanley et al., 2015), while individuals with a supernumerary Y chromosome (XYY) have an increased TBV relative to controls (Bryant et al., 2012). ASD has consistently been associated with larger TBV (Fidler et al., 2000; Hazlett et al., 2006; Lainhart et al., 2006). Bryant and colleagues (2012) suggested a potential link between the larger brain size found in XYY males and their higher rates of ASD (see Table II). 
However, other sex chromosome aneuploidies also increase the risk of ASD but show reduced rather than increased TBV. As such, no causal relationship can be established between increased TBV and ASD in individuals with sex chromosome aneuploidies.

The reduction in TBV observed in individuals with XXY, XXX, and XXYY has been attributed to a combination of insufficient testosterone and to the dosage effects of X-linked genes. Females with XXX, who have normal pubertal development, also show TBV reductions suggesting that hormonal factors alone cannot explain the reduction. However, gray matter deficits in females with XXX are less than for XXY males (Patwardhan et al., 2002). Additionally, gray matter reductions in males with Klinefelter syndrome (XXY) who have received testosterone supplements are less pronounced than in those who have not (Patwardhan et al., 2000), suggesting that insufficient testosterone is indeed an additional contributor to small TBV.

Normal sex differences are also reported in neural substructures, particularly in brain areas that are part of the limbic and language systems (Ruigrok et al., 2014). Limbic and language systems are particularly affected in individuals with sex chromosomal aneuploidies. For example, reduced amygdala size has been reported for males with XXY (Patwardhan et al., 2002) (although DeLisi et al. [2005] found no difference), while girls with Turner syndrome have an increased amygdala volume (Cutter et al., 2006; Knickmeyer and Davenport, 2011; Lepage et al., 2013). Females with an XXX anomaly tend to have a reduced amygdala volume, but the difference is small (Patwardhan et al., 2002). The observation that the development of the amygdala is susceptible to being affected in individuals with sex chromosomal aneuploidies is interesting as the amygdala is involved in the cognitive responses to facial expressions and emotional stimuli; it responds preferentially to fearful faces over other facial expressions (Zald, 2003). Emotional facial recognition (especially the recognition of fear) is impaired in girls with Turner syndrome, as is the ability measured by the "reading the mind in the eyes" task (Lawrence et al., 2003). A similar pattern of deficit is found in individuals of both sexes with ASD (Baron-Cohen, 1996; Howard et al., 2000). This suggests that the structural abnormalities of the amygdala observed in females with Turner syndrome may contribute to the ASD symptomatology associated with the syndrome (Skuse et al, 2005).

Girls with X monosomy are reported to have reduced gray and white matter volume in the parietal and occipital cortices (Cutter et al., 2006; Knickmeyer and Davenport, 2011; Lepage et al., 2013). The parietal cortex forms part of the dorsal processing stream, also known as the "where" pathway, involved in spatial processing (Mishkin et al., 1983; Ungerleider and Haxby, 1994). Visuospatial abilities are a relative weakness in girls with Turner syndrome (Hong et al., 2011). By comparison, individuals with XXY, XYY, XXX, and XXYY have relatively spared parietal gray and white matter volumes (Bryant et al., 2012; Lenroot et al., 2014; Hanley et al., 2015), and visuospatial abilities are a relative strength in these conditions (see Table I).

Males with XXY, XYY, and XXYY syndromes all have reduced volume in the frontotemporal regions (DeLisi et al., 2005; Bryant et al., 2012; Hanley et al., 2015). Temporal structures are particularly strongly affected; for instance, in XXY syndrome, the posterior superior temporal gyrus (STG) is reduced compared with age-matched controls (DeLisi et al., 2005). Males with XXY who had received testosterone treatment do not show a reduced temporal and STG volume (Patwardhan et al., 2000; Steinman et al., 2009), suggesting that the hormonal effects on the development of these structures are significant. However, hypogonadism cannot fully account for the findings; males with XYY (who experience normal pubertal maturation) show similarly reduced frontotemporal volumes (Bryant et al., 2012). The reduction in temporal volumes, and specifically changes in the posterior STG, is of particular interest given the impaired language abilities observed in these individuals. The temporal lobe and the STG are important structures for language processing (Binder et al., 1997) and include Wernicke's area and the planum temporale in the posterior STG (Wernicke, 1874).

\section{Conclusions}

For reasons that are not yet understood, there is an excessive proportion of genes on the $\mathrm{X}$ chromosome that are associated with the development of intelligence, with no obvious links to other significant biological functions (Lubs 
et al., 2012). Mutations in autosomal genes that impact neurodevelopment are usually "syndromic" in character; they are associated not only with mental retardation but also with somatic anomalies or overt disruption to structural brain development. This is not the case with many X-linked mutations, of which up to two-thirds result in intellectual disability but few somatic phenotypic markers apart from short stature and microcephaly or macrocephaly.

Sex chromosome aneuploidy, unlike autosomal aneuploidy, is comparatively well tolerated. Disteche (2012) posited that this was due to the paucity of essential genes on the $\mathrm{Y}$, and inactivation of all but one upregulated $\mathrm{X}$ copy per diploid genome; the fact that $\mathrm{X}$ monosomy causes a recognizable syndrome with rather specific deficits in terms of visuospatial cognition and social intelligence seems to indicate that dosage-sensitive genes affecting these skills do exist. Although genes that escape $\mathrm{X}$-inactivation across and within populations, and hence could be candidates for haploinsufficiency, are now being recognized (Zhang et al., 2013), we have little or no idea how they contribute to brain development in humans. Clues are, however, coming from novel approaches to discovering the expression patterns of $\mathrm{X}$ and $\mathrm{Y}$ homologs in mouse brain (Berletch et al., 2015).

There is evidence that subtle functionally polymorphic variations do occur in X-linked genes that influence cognition and behavior. This comes from clues that deleterious mutations in those same genes lead to serious learning difficulties. Potentially, such gene variants could have relatively specific modulating influences on intellectual or social abilities (Johnston et al., 2008). The role played by genes that are not subject to X-inactivation (hence, normally expressed from both $\mathrm{X}$ chromosomes in females) are of particular interest; there are proportionately about five times as many such genes in humans as in mice.

We can get clues about how X-inactivation systems are regulated by studying the mechanisms of X-linked gene regulation in animal models (Lin et al., 2007; Reinius et al., 2010; Mank, 2013; Davies, 2013). X-linked genes may have particular importance for regulating the development of higher cognitive systems, and for individual differences in such systems' functional capacity. An understanding of why such specific cognitive and social phenotypes result from the consequence of $\mathrm{X}$ chromosome aneuploidy would illuminate the broad field of human neurodevelopmental disorders.

\section{Conflict of interest}

This literature review was conducted in the absence of any commercial or financial relationships that could be construed as a potential conflict of interest.

\section{Role of authors}

All authors had full access to all the literature cited in the study and take responsibility for the integrity of the information reviewed and the accuracy of the summary of literature provided here. Drafting of the manuscript: FP, JW, and DHS. Critical revision of the manuscript for important intellectual content: FP, JW, DHS. Study supervision: DHS. 


\section{References}

Abramsky L, Chapple J. 1997. 47, XXY (Klinefelter syndrome) and 47, XYY: estimated rates of and indication for postnatal diagnosis with implications for prenatal counselling. Prenat Diagn 17:363-368.

Bardsley MZ, Kowal K, Levy C, Gosek A, Ayari N, Tartaglia N, Lahlou N, Winder B, Grimes S, Ross JL. 2013. 47, XYY syndrome: clinical phenotype and timing of ascertainment. J Pediatr 163:1085-1094.

Baron-Cohen S. 1996. Reading the mind in the face: a cross-cultural and developmental study. Vis Cogn 3:39-60.

Bellott DW, Hughes JF, Skaletsky H, Brown LG, Pyntikova T, Cho TJ, Koutseva N, Zaghlul S, Graves T, Rock S. 2014. Mammalian Y chromosomes retain widely expressed dosage-sensitive regulators. Nature 508:494.

Bender B, Fry E, Pennington B, Puck M, Salbenblatt J, Robinson A. 1983. Speech and language development in 41 children with sex chromosome anomalies. Pediatrics 71:262-267.

Bender BG, Linden MG, Robinson A. 1993. Neuropsychological impairment in 42 adolescents with sex chromosome abnormalities. Am J Med Genet 48:169-173.

Berletch JB, Ma W, Yang F, Shendure J, Noble WS, Disteche CM, Deng X. 2015. Escape from X inactivation varies in mouse tissues. PLoS Genet 11:e1005079.

Binder JR, Frost JA, Hammeke TA, Cox RW, Rao SM, Prieto T.

1997. Human brain language areas identified by functional magnetic resonance imaging. J Neurosci 17:353-362.

Bishop DV, Scerif G. 2011. Klinefelter syndrome as a window on the aetiology of language and communication impairments in children: the neuroligin-neurexin hypothesis. Acta Paediatr 100:903-907.

Bishop DV, Jacobs PA, Lachlan K, Wellesley D, Barnicoat A, Boyd PA, Fryer A, Middlemiss P, Smithson S, Metcalfe $\mathrm{K}$, et al. 2011. Autism, language and communication in children with sex chromosome trisomies. Arch Dis Child 96:954-959.

Brown WE, Kesler SR, Eliez S, Warsofsky IS, Haberecht M, Patwardhan A, Ross JL, Neely EK, Zeng SM, Yankowitz J, et al. 2002. Brain development in Turner syndrome: a magnetic resonance imaging study. Psychiatr Res 116:187196.

Bruining H, Swaab H, Kas M, van Engeland H. 2009. Psychiatric characteristics in a self-selected sample of boys with Klinefelter syndrome. Pediatrics 123:e865-e870.

Bryant DM, Hoeft F, Lai S, Lackey J, Roeltgen D, Ross J, Reiss AL. 2012. Sex chromosomes and the brain: a study of neuroanatomy in XYY syndrome. Dev Med Child Neurol 54:1149-1156.

Burnett AC, Reutens DC, Wood AG. 2010. Social cognition in Turner syndrome. J Clin Neurosci 17:283-286.

Christensen DL, Baio J, Braun KV, Bilder D, Charles J, Constantino JN, Daniels J, Durkin MS, Fitzgerald RT, KurziusSpencer M, et al. 2016. Prevalence and characteristics of autism spectrum disorder among children aged 8 years Autism and Developmental Disabilities Monitoring Network, 11 sites, United States, 2012. Morbidi MMWR Surveill Summ. 65:1-23.

Cordeiro L, Tartaglia N, Roeltgen D, Ross J. 2012. Social deficits in male children and adolescents with sex chromosome aneuploidy: a comparison of XXY, XYY, and XXYY syndromes. Res Dev Disabil 33:1254-1263.

Craig IW, Haworth CM, Plomin R. 2009. Commentary on "A role for the X chromosome in sex differences in variability in general intelligence?” (Johnson et al., 2009). Perspect Psychol Sci 4:615-621.

Creswell CS, Skuse DH. 1999. Autism in association with Turner syndrome: genetic implications for male vulnerability to pervasive developmental disorders. Neurocase 5:511-518.

Crow TJ. 2013. The XY gene hypothesis of psychosis: origins and current status. Am J Med Genet B Neuropsychiatr Genet 162:800-824. Cutter WJ, Daly EM, Robertson DM, Chitnis XA, van Amelsvoort TA, Simmons A, Ng VW, Williams BS, Shaw P, Conway GS, et al. 2006. Influence of X chromosome and hormones on human brain development: a magnetic resonance imaging and proton magnetic resonance spectroscopy study of Turner syndrome. Biol Psychiatr 59:273-283. 
Davies W. 2013. Using mouse models to investigate sex-linked genetic effects on brain, behaviour and vulnerability to neuropsychiatric disorders. Brain Res Bull 92:12-20.

DeLisi LE, Maurizio AM, Svetina C, Ardekani B, Szulc K, Nierenberg J, Leonard J, Harvey PD. 2005. Klinefelter's syndrome (XXY) as a genetic model for psychotic disorders. Am J Med Genet B Neuropsychiatr Genet 135:15-23.

Deng X, Berletch JB, Nguyen DK, Disteche CM. 2014. X chromosome regulation: diverse patterns in development, tissues and disease. Nat Rev Genet 15:367.

Disteche CM. 2012. Dosage compensation of the sex chromosomes. Ann Rev Genet 46:537.

Fidler DJ, Bailey JN, Smalley SL. 2000. Macrocephaly in autism and other pervasive developmental disorders. Dev Med Child Neurol 42:737-740.

Fombonne E. 2009. Epidemiology of pervasive developmental disorders. Pediatr Res 65:591-598.

Geerts M, Steyaert J, Fryns JP. 2003. The XYY syndrome: a follow-up study on 38 boys. Genet Couns 14:267-279.

Giedd JN, Castellanos FX, Rajapakse JC, Vaituzis AC, Rapoport JL. 1997. Sexual dimorphism of the developing human brain. Prog Neuropsychopharmacol Biol Psychiatry 21:1185-1201.

Giedd JN, Clasen LS, Wallace GL, Lenroot RK, Lerch JP, Wells EM, Blumenthal JD, Nelson JE, Tossell JW, Stayer C, et al. 2007. XXY (Klinefelter syndrome): a pediatric quantitative brain magnetic resonance imaging case-control study. Pediatrics 119:e232-e240.

Giummo J, Johnson W. 2012. Testing for evidence of an X-linked genetic basis for a greater proportion of males with high cognitive ability. Behav Genet 42:808-819.

Graham JM Jr, Bashir AS, Stark RE, Silbert A, Walzer S. 1988. Oral and written language abilities of XXY boys: implications for anticipatory guidance. Pediatrics 81:795-806.

Green T, Bade Shrestha S, Chromik LC, Rutledge K, Pennington BF, Hong DS, Reiss AL. Elucidating X chromosome influences on attention deficit hyperactivity disorder and executive function. J Psychiatr Res 68:217-225.

Gregg C, Zhang J, Butler JE, Haig D, Dulac C. 2010. Sex-specific parent-of-origin allelic expression in the mouse brain. Science 329: 682-685.

Hanley AP, Blumenthal JD, Lee NR, Baker EH, Clasen LS, Giedd JN. 2015. Brain and behavior in 48, XXYY syndrome. Neuroimage Clin 8:133-139.

Hazlett HC, Poe MD, Gerig G, Smith RG, Piven J. 2006. Cortical gray and white brain tissue volume in adolescents and adults with autism. Biol Psychiatr 59:1-6.

Hedges LV, Nowell A. 1995. Sex differences in mental test scores, variability, and numbers of high-scoring individuals. Science 269:41-45.

Hong DS, Dunkin B, Reiss AL. 2011. Psychosocial functioning and social cognitive processing in girls with Turner syndrome. J Dev Behav Pediatr 32:512-520.

Howard MA, Cowell PE, Boucher J, Broks P, Mayes A, Farrant A, Roberts N. 2000. Convergent neuroanatomical and behavioural evidence of an amygdala hypothesis of autism. Neuroreport 11:2931-2935. Johnson W, Carothers A, Deary IJ. 2009. A role for the X chromosome in sex differences in variability in general intelligence? Perspect Psychol Sci 4:598-611.

Johansson MM, Lundin E, Qian X, Mirzazadeh M, Halvardson J, Darj E, Feuk L, Nilsson M, Jazin E. 2016. Spatial sexual dimorphism of $\mathrm{X}$ and $\mathrm{Y}$ homolog gene expression in the human central nervous system during early male development. Biol Sex Differ 7:1-17.

Johnston CM, Lovell FL, Leongamornlert DA, Stranger BE, Dermitzakis ET, Ross MT. 2008. Large-scale population study of human cell lines indicates that dosage compensation is virtually complete. PLoS Genet 4:e9.

Knickmeyer RC, Davenport M. 2011. Turner syndrome and sexual differentiation of the brain: implications for understanding male-biased neurodevelopmental disorders. J Neurodev Disord 3:293-306.

Kopsida E, Stergiakouli E, Lynn PM, Wilkinson LS, Davies W. 2009. The role of the Y chromosome in brain function. Open Neuroendocrinol J 2:20. 
Lainhart JE, Bigler ED, Bocian M, Coon H, Dinh E, Dawson G, Deutsch CK, Dunn M, Estes A, Tager-Flusberg H, et al. 2006. Head circumference and height in autism: a study by the Collaborative Program of Excellence in Autism. Am J Med Genet A 140:2257-2274. Lawrence K, Campbell R, Swettenham J, Terstegge J, Akers R, Coleman M, Skuse D. 2003. Interpreting gaze in Turner syndrome: impaired sensitivity to intention and emotion, but preservation of social cueing. Neuropsychologia 41:894-905.

Lehrke R. 1972. A theory of X-linkage of major intellectual traits. Am J Ment Defic. 76:611-619.

Lenroot RK, Blumenthal JD, Wallace GL, Clasen LS, Lee NR, Giedd JN. 2014. A case-control study of brain structure and behavioral characteristics in 47,XXX syndrome. Genes Brain Behav 13:841-849.

Lepage JF, Mazaika PK, Hong DS, Raman M, Reiss AL. 2013. Cortical brain morphology in young, estrogen-naive, and adolescent, estrogentreated girls with Turner syndrome. Cereb Cortex 23:2159-2168.

Lepage JF, Lortie M, Deal CL, Theoret H. 2014. Empathy, autistic traits, and motor resonance in adults with Turner syndrome. Soc Neurosci 9: 601-609.

Lin A, Clasen L, Lee NR, Wallace GL, Lalonde F, Blumenthal J, Giedd JN, Raznahan A. 2015. Mapping the stability of human brain asymmetry across five sex-chromosome aneuploidies. J Neurosci 35:140-145.

Lin H, Gupta V, VerMilyea MD, Falciani F, Lee JT, O’Neill LP, Turner BM. 2007. Dosage compensation in the mouse balances up-regulation and silencing of X-linked genes. PLoS Biol 5:e326.

Linden MC, Bender BG, Robinson A. 1995. Sex chromosome tetrasomy and pentasomy. Pediatrics 96:672-682.

Lubs HA, Stevenson RE, Schwartz CE. 2012. Fragile X and X-linked intellectual disability: four decades of discovery. Am J Hum Genet 90: 579-590.

Mank JE. 2013. Sex chromosome dosage compensation: definitely not for everyone. Trends Genet 29:677-683.

Margari L, Lamanna AL, Craig F, Simone M, Gentile M. 2014. Autism spectrum disorders in XYY syndrome: two new cases and systematic review of the literature. Eur J Pediatr 173:277-283.

Marzelli MJ, Hoeft F, Hong DS, Reiss AL. 2011. Neuroanatomical spatial patterns in Turner syndrome. Neuroimage 55:439-447.

Migeon B. 2014. Females are mosaics: X inactivation and sex differences in disease. Oxford (UK): Oxford University Press.

Mishkin M, Ungerleider LG, Macko KA. 1983. Object vision and spatial vision: two cortical pathways. Trends Neurosci 6:414-417.

Moreno-De-Luca A, Evans DW, Boomer K, Hanson E, Bernier R, Goin-Kochel RP, Myers SM, Challman TD, MorenoDe-Luca D, Slane MM. 2015. The role of parental cognitive, behavioral, and motor profiles in clinical variability in individuals with chromosome 16p11. 2 deletions. JAMA Psychiatry 72:119-126.

Nielsen J, Wohlert M. 1991. Chromosome abnormalities found among 34910 newborn children: results from a 13-year incidence study in A rhus, Denmark. Hum Genet 87:81-83.

Nøvik TS, Hervas A, Ralston SJ, Dalsgaard S, Rodrigues Pereira R, Lorenzo MJ; ADORE Study Group. Influence of gender on attentiondeficit/hyperactivity disorder in Europe - ADORE. Eur Child Adolesc Psychiatry 15:i15-i24.

Otter M, Schrander-Stumpel CTRM, Curfs LMG. 2010. Triple X syndrome: a review of the literature. Eur J Hum Genet 18:265-271.

Patwardhan A, Eliez S, Bender B, Linden M, Reiss A. 2000. Brain morphology in Klinefelter syndrome: extra X chromosome and testosterone supplementation. Neurology 54:2218-2223.

Patwardhan AJ, Brown WE, Bender BG, Linden MG, Eliez S, Reiss AL. 2002. Reduced size of the amygdala in individuals with 47,XXY and 47,XXX karyotypes. Am J Med Genet 114:93-98.

Polani P. 1977. Abnormal sex chromosomes, behaviour and mental disorder. In: Tanner J, editor. Developments in psychiatric research. London (UK): Hodder and Stoughton. p. 89-128.

Ratcliffe S. 1999. Long term outcome in children of sex chromosome abnormalities. Arch Dis Childhood 80:192-195. 
Raznahan A, Lee NR, Greenstein D, Wallace GL, Blumenthal JD, Clasen LS, Giedd JN. 2016. Globally divergent but locally convergent X- and Y-chromosome influences on cortical development. Cereb Cortex 26:70-79.

Reinius B, Shi C, Hengshuo L, Sandhu KS, Radomska KJ, Rosen GD, Lu L, Kullander K, Williams RW, Jazin E. 2010. Female-biased expression of long non-coding RNAs in domains that escape X-inactivation in mouse. BMC Genomics 11:614.

Ross JL, Roeltgen DP, Kushner H, Zinn AR, Reiss A, Bardsley MZ, McCauley E, Tartaglia N. 2012. Behavioral and social phenotypes in boys with 47,XYY syndrome or 47,XXY Klinefelter syndrome. Pediatrics 129:769-778.

Ross JL, Tartaglia N, Merry DE, Dalva M, Zinn AR. 2015. Behavioral phenotypes in males with XYY and possible role of increased NLGN4Y expression in autism features. Genes Brain Behav 14:137-144.

Rovet JF. 1990. The cognitive and neuropsychological characteristics of females with Turner syndrome. In: Berch DB, Bender BG, editors. Sex chromosome abnormalities and human behavior: psychological studies. Boulder (CO): AAAS/Westview Press. p. 38-77.

Rovet JF. 1993. The psychoeducational characteristics of children with Turner syndrome. J Learn Disabil 26:333-341.

Rovet J, Netley C, Bailey J, Keenan M, Stewart D. 1995. Intelligence and achievement in children with extra X aneuploidy: a longitudinal perspective. Am J Med Genet 60:356-363.

Ruigrok AN, Salimi-Khorshidi G, Lai MC, Baron-Cohen S, Lombardo MV, Tait RJ, Suckling J. 2014. A meta-analysis of sex differences in human brain structure. Neurosci Biobehav Rev 39:34-50.

Saad K, Abdelrahman AA, Abdel-Raheem YF, Othman ER, Badry R, Othman HAK, Sobhy KM. 2013. Turner syndrome: review of clinical, neuropsychiatric, and EEG status: an experience of tertiary center. Acta Neurol Belg 114:1-9.

Skuse DH. 2005. X-linked genes and mental functioning. Hum Mol Genet 14 Spec No 1:R27-R32.

Skuse DH. 2009. Psychological and psychiatric aspects of Turner syndrome. In: Gravholt CH, editor. Turner-Know Your Body! An Information Book on Turner Syndrome. Bagsværd (Denmark): Novo Nordisk.

Skuse DH, James RS, Bishop DV, Coppin B, Dalton P, Aamodt-Leeper G, Bacarese-Hamilton M, Creswell C, McGurk R, Jacobs PA. 1997. Evidence from Turner syndrome of an imprinted X-linked locus affecting cognitive function. Nature 387:705-708.

Skuse DH, Morris JS, Dolan RJ. 2005. Functional dissociation of amygdala-modulated arousal and cognitive appraisal, in Turner syndrome. Brain 128:2084-2096.

Steinman K, Ross J, Lai S, Reiss A, Hoeft F. 2009. Structural and functional neuroimaging in Klinefelter (47,XXY) syndrome: a review of the literature and preliminary results from a functional magnetic resonance imaging study of language. Dev Disabil Res Rev 15:295-308.

Talebizadeh Z, Lam DY, Theodoro MF, Bittel DC, Lushington GH, Butler MG. 2006. Novel splice isoforms for NLGN3 and NLGN4 with possible implications in autism. J Med Genet 43:e21.

Tartaglia N, Davis S, Hench A, Nimishakavi S, Beauregard R, Reynolds A, Fenton L, Albrecht L, Ross J, Visootsak J. 2008a. A new look at XXYY syndrome: medical and psychological features. Am J Med Genet A 146:1509-1522.

Tartaglia N, Davis S, Hench A, Nimishakavi S, Beauregard R, Reynolds A, Fenton L, Albrecht L, Ross J, Visootsak J, et al. 2008b. A new look at XXYY syndrome: medical and psychological features. Am J Med Genet A 146A:15091522 .

Tartaglia N, Cordeiro L, Howell S, Wilson R, Janusz J. 2010a. The spectrum of the behavioral phenotype in boys and adolescents 47, XXY (Klinefelter syndrome). Pediatr Endocrinol Rev 8:151.

Tartaglia NR, Howell S, Sutherland A, Wilson R, Wilson L. 2010b. A review of trisomy X (47, XXX). Orphanet J Rare Dis 5:1.

Tartaglia NR, Ayari N, Hutaff-Lee C, Boada R. 2012. Attention-deficit hyperactivity disorder symptoms in children and adolescents with sex chromosome aneuploidy: XXY, XXX, XYY, and XXYY. J Dev

Behav Pediatr 33:309-318. 
Temple CM, Shephard EE. 2012. Exceptional lexical skills but executive language deficits in school starters and young adults with Turners syndrome: implications for X chromosome effects on brain function. Brain Lang 120:345-359.

Tokita MJ, Sybert VP. 2016. Postnatal outcomes of prenatally diagnosed 45, X/46, XX. Am J Med Genet A 170A:11961201.

Ungerleider LG, Haxby JV. 1994. 'What' and 'where' in the human brain. Curr Opin Neurobiol 4:157-165. WarwickMM,DoodyGA,LawrieSM,KestelmanJN,BestJJ,

Johnstone EC. 1999. Volumetric magnetic resonance imaging study of the brain in subjects with sex chromosome aneuploidies. J Neurol Neurosurg Psychiatry 66:628-632.

Wernicke C. 1874. Der aphasische symptomencomplex, eine psychologische studie auf anatomischer basis, von Dr. C. Wernicke. Wrocław (Poland): M. Cohn und Weigert.

Wu H, Luo J, Yu H, Rattner A, Mo A, Wang Y, Smallwood PM,

Erlanger B, Wheelan SJ, Nathans J. 2014. Cellular resolution maps of X chromosome inactivation: implications for neural development, function, and disease. Neuron 81:103-119.

Zald DH. 2003. The human amygdala and the emotional evaluation of sensory stimuli. Brain Res Rev 41:88-123.

Zhang Y, Morales AC, Jiang M, Zhu Y, Hu L, Urrutia AO, Kong X, Hurst LD. 2013. Genes that escape X-inactivation in humans have high intraspecific variability in expression, are associated with mental impairment but are not slow evolving. Mol Biol Evol 30:2588-2601. 